On the Periphery or at the Centre?: Ideas for Improving the Physical and Interpersonal Environments for Lesbian, Gay, Bi-sexual, and Transsexual/gender Students at a New Zealand Secondary School.

New Zealand Journal of Teachers' Work, Volume 14, Issue 2, 99-113, 2017

\title{
WENDY HEMI
}

\author{
ANITA MORTLOCK \\ Victoria University, Wellington
}

\begin{abstract}
Despite mandates that require schools to be safe places for all students, issues persist around the provision of safety for lesbian, gay, bi-sexual, trans-sexual, and trans-gendered students and staff. The current study reports the initial two stages of an action research project undertaken in a New Zealand secondary school, which aimed to enhance the interpersonal and physical environments for students with diverse gender identities and sexual orientations. The first phase consisted of data gathering, comprising an evaluation of the physical environment and a survey issued to students and staff. The second phase was the development of a plan for ongoing action and improvement, consisting of education, provision of safe spaces and meaningful support, and artefacts that communicate tolerance.
\end{abstract}

\section{INTRODUCTION}

New Zealand schools are meant to be safe places for all students and staff, a requirement mandated by the National Education Guidelines and Regulations and further affirmed by New Zealand's commitment as a signatory to the United Nations Convention on the Rights of the Child (UNCROC). Furthermore, this requirement is stipulated in the Human Rights Act 1993, and the Bill of Rights Act 1990 (Nairn \& Smith, 2010). That notwithstanding, New Zealand and international research indicates that for lesbian, gay, bi-sexual, transgender and transsexual (LGBT) students and staff members, the school environment can be unsafe. According to the Youth 2012 study (Clark et al., 2013), approximately $1 \%$ of secondary school students identify as transgender, and $4 \%$ of secondary school students are attracted to the same sex or both sexes.

Youth in New Zealand are struggling and yet it is statistically more so for those identifying as LGBT. We do not intend here to stigmatise LGBT youth, which Lucassen, Clark, Moselen, Robinson, and The Adolescent Health Research Group (2014) rightly describe as an "important and vibrant subpopulation" (p. 13); rather we wish to highlight the critical importance of addressing the negative societal factors which expose LGBT people to physical 
and emotional harm (see Lucassen, et al. 2014). For instance, there are many concerning statistics reported by Lucassen et al. (2014), some of which follow. While a great deal of LGBT youth reported favourable relationships with their families, these data were not as high compared with their heterosexual peers and LGBT youth were significantly more likely to run away from home (25.8\%) compared with youth attracted to the opposite sex (10.6\%). In addition, LGBT youth were less likely to report good or excellent general health and emotional wellbeing compared with heterosexual peers. Despite this they reported more difficulties in accessing healthcare than opposite-sex attracted youth. Most students reported that they were not depressed or had attempted suicide, however, LGBT students were more highly represented in those that reported suicide attempts (e.g. 18.3\% LGBT students reported attempting suicide compared with $3.8 \%$ of opposite-sex attracted students). Moreover, the numbers of LGBT students reporting depression increased from 2001 and their use of alcohol and other drugs was generally higher than their heterosexual peers. A significant concern is that in 2012, 57.9\% of LGBT students feared bullying at school and $43.3 \%$ had been deliberately physically hurt in the previous 12 months. Moreover, 16.5\% reported that they were bullied at least weekly because they were gay (Lucassen, et al., 2014). Such bullying not only generates fear for victims, but also generates feelings of inferiority, leading Pamela Smith (1999) to describe the impact on LGBT students as being "truly lynched spiritually, emotionally and mentally" (p. 32, cited in Higdon, 2011, p. 45).

It is not only bullying that can contribute to an unsafe environment for LGBT students, rather positioning heterosexuality as the norm or preferred sexual orientation (otherwise known as heteronormativity) can communicate to students that anything 'other' is unacceptable, having a direct bearing on a person's identity and self-esteem (Gunn \& Smith, 2015). Indeed, heteronormativity is evident in the nuanced dimensions of 'space' and 'place' within schools; i.e. it must be examined in the material, interpersonal, and other levels of environment (Gunn \& Smith, 2015). Deconstructing heteronormativity is an important long-term strategy if we are to achieve a truly safe school environment for all (Gunn \& Smith, 2015; Nairn \& Smith, 2010). In fact, Nairn and Smith stated that "heterosexuality is 'the problem' rather than homosexuality, and that if heterosexuality was not taken for granted as 'the norm'; other sexualities might not be understood as abnormal" (2010, p. 134). One of the difficulties is that heteronormativity and gender essentialism are evident even amongst our youngest learners. Gunn and McNaughton (2007) found that New Zealand pre-school children had strong views about how boys and girls should act in relation to their gender. Moreover, teachers' responses might compound the children's assumptions; for instance, boys dressing up in 'girl's' clothing might be dismissed as 'just playing'. This response potentially undermines boys' ability to realise any form of gender fluidity (Gunn \& MacNaughton, 2007, p. 130).

We do not need to look too far within our own cultural context to find challenges to heteronormative stances. Historically, Māori appeared to accept variations in sexual identity, expression and preference. This is evinced in art forms such as carvings, paintings, whakairo, and archival material that described Māori sexuality as it was lived and experienced in pre-European times. Many depict images of same-sex relationships and there are written 
records that acknowledge Māori society embracing and celebrating sexuality in all its diversity, including multiple partners. The imposition of a colonialist view of sexuality has meant that, "traditional views and understandings of Māori sexuality have become, blurred, misinterpreted or completely lost" (Aspin \& Hutchings, 2007, p. 421). As such, biculturalism and cultural safety in educational settings should examine traditional and contemporary Māori views and understandings on sexuality.

The issue of safety for LGBT secondary school students in New Zealand was a focus in Nairn and Smith's (2010) nation-wide study, undertaken with 821 students aged 15-16 years and 438 staff members. The study issued questionnaires that focused on how each respondent described attitudes towards LGBT students. The findings reflected that very few students and staff perceived that LGBT students were safe at school, being subject to both subtle and extreme forms of intimidatory behaviour. The two most prevalent behaviours were: (1) the maintenance of silence, and (2) harassment, particularly verbal, which included the "pathologisation of homosexuality and the erasure of the feminine from the male psyche" (p. 146). Notwithstanding, many respondents were surprised at the notion that LGBT students would feel unsafe at school, meaning that heterosexual students might not fully understand the impact of prejudiced or heteronormative discourses on LGBT people. An important point that Nairn and Smith (2010) raised is that in order to understand LGBT students' lived experience of school, all students' views must be respectfully heard. Only then can discourses counter to LGBT students' safety come to light, be understood, and the effects ameliorated. The present study asked, (1) 'what are students' and staff members' views about the experiences of LGBT students at one secondary school?" and (2) "how can our understanding of these views be used to enhance the wellbeing of LGBT students at school?".

\section{METHODOLOGY}

The aim of the present study was to gather data on LGBT people's safety within a New Zealand secondary school in order to continuously improve the climate for LGBT students and staff. At the start of the study, a new LGBT support group had been established in the school at the request of some of the students. In addition, the staff had undertaken professional development, which focused on understanding sexual orientation and gender identity, as well as the strategies that teachers can use to promote a safe environment for all students. The school had 67 staff, comprising teachers, administrators, teacher aides, and caretakers. There were 330 students. The first author participated in the school environment as a paid employee throughout the duration of the study, hence site selection was the researcher's workplace and participants, their colleagues. Implications of this are discussed later in the article.

The study was informed by sociocultural theory, which posits that social interaction is not only influenced by social and physical contexts, but that individuals within that context make sense of and internalise the knowledge that they construct in the process of interacting with people, places, and things. In turn, individuals act on the environment based on their constructed knowledge (Lantolf, 2000). As such, supportive interactions most likely contribute to an individual's affirming self-knowledge as well as that pertaining to the wider 
world; whereas hostile or dismissive interactions potentially achieve the converse (Skinner, Wellborn, \& Connell, 1990). Such ideas are emphasised in the New Zealand Curriculum, which states that, "learning is inseparable from its social and cultural context. Students learn best when they feel accepted" (Ministry of Education, 2007, p. 34). Given that interactions are situated within a physical place and space in time, it was important to examine both the physical and the interpersonal environments.

Once the focus had been chosen, the first author gathered data and systematically reported back to staff, board, and the student group. An action research method was used, whereby the research focus arises from an area of concern for the research participants. It is often described as emancipatory because it requires individuals to examine their preconceived theories and beliefs in order to effect positive changes. Often, action research involves several phases that involve reflection and action (McNiff, 2013). In the present study, the focus of improving the social context for LGBT students and staff arose from the wider context, including issues raised by students. This bears some resemblance to Timperley, Kaser, \& Halberts's (2014) notion that effective change necessitates ensuring that students have agency to identify and help address concerns and issues at their schools. Another key phase in action research is planning for change, which leads to action, and further reflection (McNiff, 2013). This article reports the first two stages of the research, i.e. the data gathering and planning for improvement.

Action research is not without its challenges; one of the predominant challenges in the present study was the issue of the first author conducting research in an environment within which she was employed. In the first instance, the separation between the researcher and the researched disappears. As the first author was an insider to the educational setting, it is possible that her expertise had more weight more so than, say, an external consultant. There is also the potential for members of the community to avoid sensitive topics because of the existing relationship. Finally, shared norms might be expressed tacitly rather than communicated explicitly (see Mercer, 2007). In her seminal article, Grundy (1994) noted that language can become a site of struggle when the researcher is an insider. Indeed, the first author found that generally accepted respectful vocabularly concerning LGBT students was not neccesarily shared amongst all members of the community; therefore there was potential for misunderstandings or insult. The first researcher had to then tread the careful path of modelling acceptable language whilst being mindful about power relations and taking on expert status that might not be assigned by the community.

A multi-pronged approach to data gathering was taken. First, the first author evaluated the physical environment; this was done by walking around the school in order to catalogue and analyse the overt and hidden messages about LGBT people that might be communicated through the artefacts occurring within the school environment, such as posters or meeting areas, as described by Chesir-Teran (2003). In addition, the school librarian was asked to identify books held by the library that portrayed LGBT people and issues. The key plot themes relating to LGBT people were documented on the books that were found. In addition, a web-based survey was issued to all students and staff, and that incorporated a range of four point ratings scales, qualitative short response questions, and checklists. Initial questions gathered demographic data, 
including whether the respondents were students or staff. Subsequent questions were designed to probe respondents' perceptions of safety within the school. Specific questions targeted the issues of acceptance and bullying towards LGBT students and canvassed the respondents for ideas to improve the climate. The survey items were consistent with the factors typically focused on in studies of school climate as described by Chesir-Teran (2003). Finally, a portfolio was developed throughout the study, which catalogued the first author's observations and reflections of the school's physical and social environment, her own role as participant researcher, and other thinking, which was provoked and developed by relevant research articles. Some of these reflections are reported in the discussion section of this article.

Ethical considerations included protecting the anonymity of the school and the research participants. As such, the role of the first author has not been disclosed in this article as it would potentially identify the school setting. Consent was gained from the school principal for the research to take place. An explanation of the survey was given at assembly and the participation of students and staff members was voluntary. Since participation was anonymous and voluntary, it was seen as consensual for those students and staff members who responded. The aims and findings of the study were reported in full to the school community and the principal's consent was sought before any dissemination of data occurred in public forums, including the present article.

\section{RESEARCH FINDINGS}

\section{Analysis of the physical environment}

The physical space of the secondary school was canvassed in order to find physical features that supported inclusion of LGBT students and adults. The first author developed a rough checklist for artefacts to look for, which included the overt and positive depiction of LGBT people or resources that potentially supported the positive identity and support of LGBT people. The checklist included, posters, library books, uniforms, provision of physical spaces, and displays as recommended by Chesir-Teran (2003). The school prominently displayed its motto and values, which advocated for support, compassion, and understanding for all of its students. Notwithstanding, few features were found that were specific to LGBT students; however, the first author identified the following:

- Four unisex toilets, that could potentially cater for gender-fluid individuals, and that were preferable to toilets that are traditionally designated 'male' and 'female'. In addition, it may be noted that unisex toilets mean trans-sexual and trans-gendered students do not have to choose between using toilets allocated to their legally assigned gender as opposed to toilets allocated to their cognitive or chosen gender.

- The Art Room walls displayed images in drawings and photographic work that could be interpreted as LGBT friendly, such as images of same-sex people holding hands. 
The school librarian was asked to identify those books about LGBT relationships held within its records, and identified four, including one that is often on display

\section{Survey findings}

There were 94 responses to the survey, comprising 74 students (22.4\%) and 20 staff $(29.8 \%)$, with the gender and ethnicity of respondents paralleling the school roll statistics.

The first question asked how safe respondents felt at school. The majority of respondents said that they felt safe personally, as seen in Figure 1. Overall, both students and staff reported feeling safe or very safe at school. A typical comment that affirmed a safe school environment was: "I feel included in the school society and feel like people care for me". Only one student felt unsafe, and this student commented, "Everyone at this school are (sic) rude and judgmental".

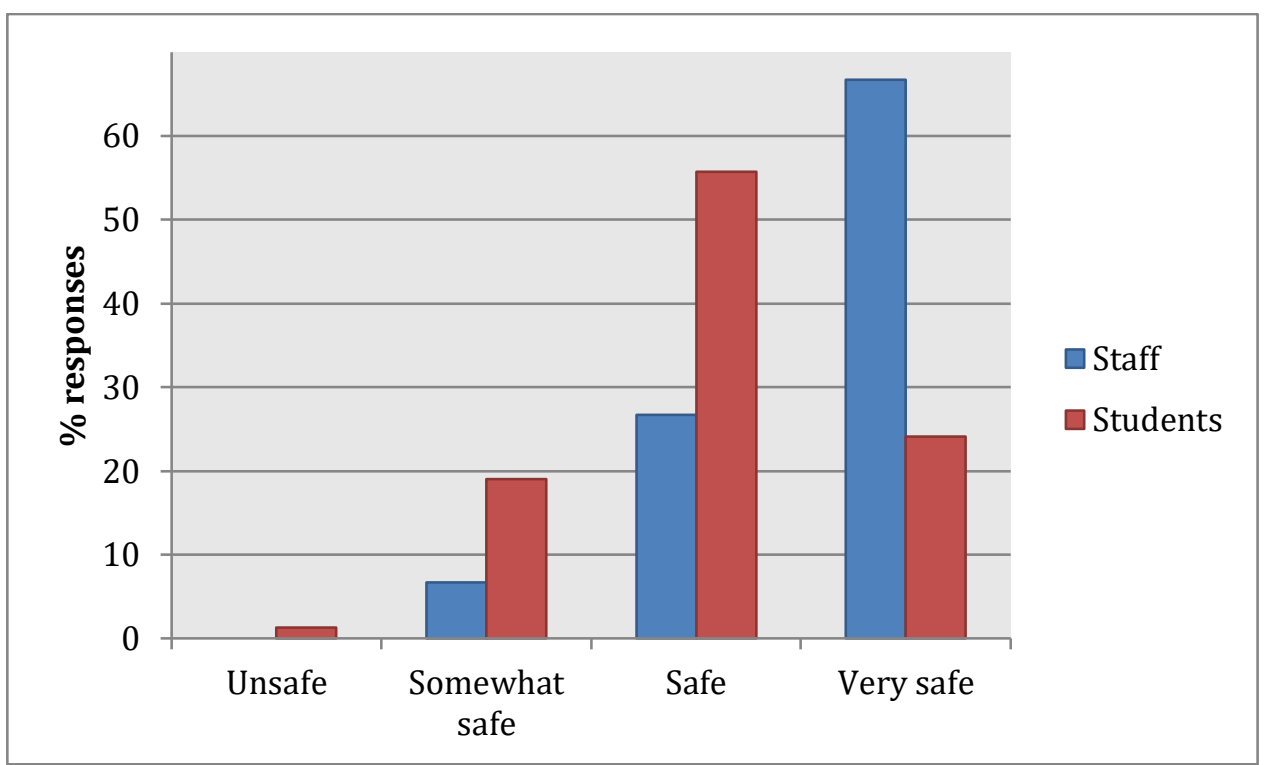

Fig. 1: Percentages of respondents' reports describing their own general feelings of safety within the school

Fewer respondents indicated that they viewed LGBT people as being safe at school, as depicted in Figure 2. The comments appeared to affirm this. Student comments included; "they [LGBT people] do get bullied a lot" and "because a lot of people judge them, differently when they are not comfortable of (sic) being gay they get made fun of more". Where staff members made comments, they indicated that safety might be associated with language; for instance, several noted that specific students used "gay" as a derogatory term, which could make LGBT people feel unsafe. 


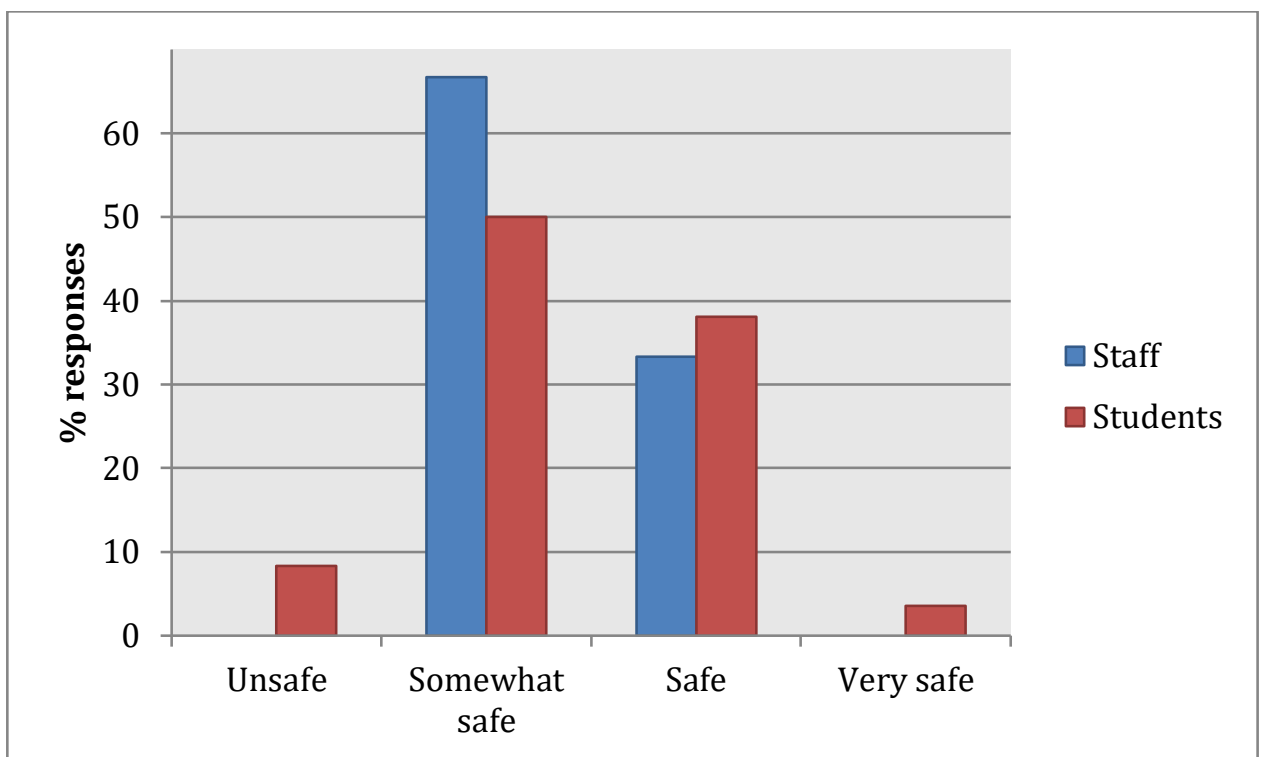

Fig. 2: Percentages of respondents views on the safety of LGBT people at the school.

It is important to note that several respondents indicated that even though they were less confident about LGBT people's feelings of safety at this specific school, their perception was that the school was better at providing for LGBT people's safety than others; for instance, "because I feel that although our school is a lot more Inclusive around LGBT students than others, I still feel as though there is room for improvement and know that as students have requested support there is clearly a need to help them feel safer". Although the focus was on LGBT people at school, comments generally referred to students only rather than staff.

When asked if they had observed bullying of LGBT people at school, $31 \%$ of the overall responses indicated that they had and $43 \%$ reported that they had not. Staff were less likely to report that they had seen bullying than students (see Figure 3). The majority of observations involved name-calling and put-downs. Examples of relevant comments included, "verbal putdowns using you're gay, you're a faggot" and "They have been verbally teased and made fun of".

Respondents were asked to rate how accepting they were towards LGBT people. The responses are represented in Figure 4. All staff indicated that they were 'accepting' or 'very accepting'. Although the majority of students indicated that they were accepting, the comments made by those who rated themselves as not accepting were concerning because they indicated the potential for emotional harm. Such comments included: "I don't like them it's just not right, they're OTT (over the top), there shouldn't be gays and lezzys at [school], poooh!" and "I think it's wrong". 


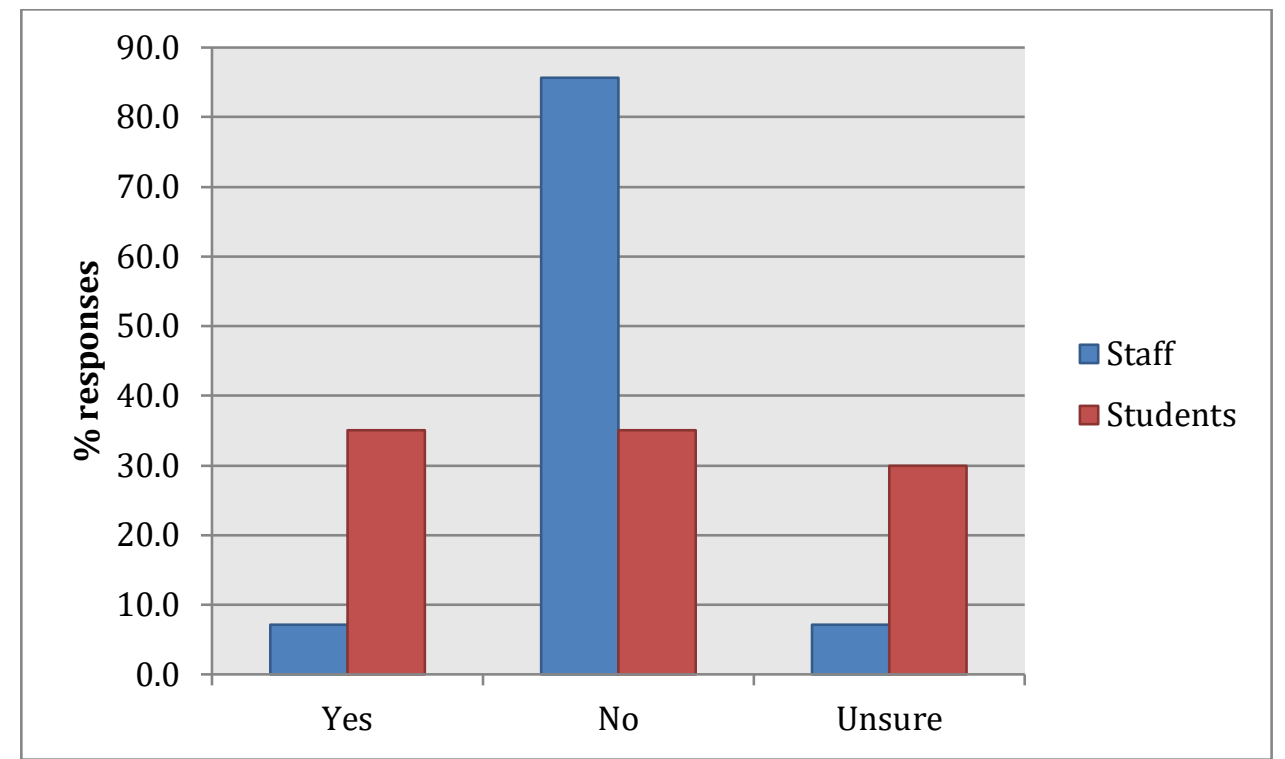

Fig. 3: Percentages of respondents' reports of observing bullying of LGBT students

When asked what could be done to make LGBT students and staff feel safer at school there were 53 responses. These responses suggested the following: use of signage, more unisex toilets, continuing to address bullying using restorative practices, have more education and talks about it, addressing LGBT issues better during health programmes, normalising it, and celebrating it (with permission). One comment summarised the general feeling:

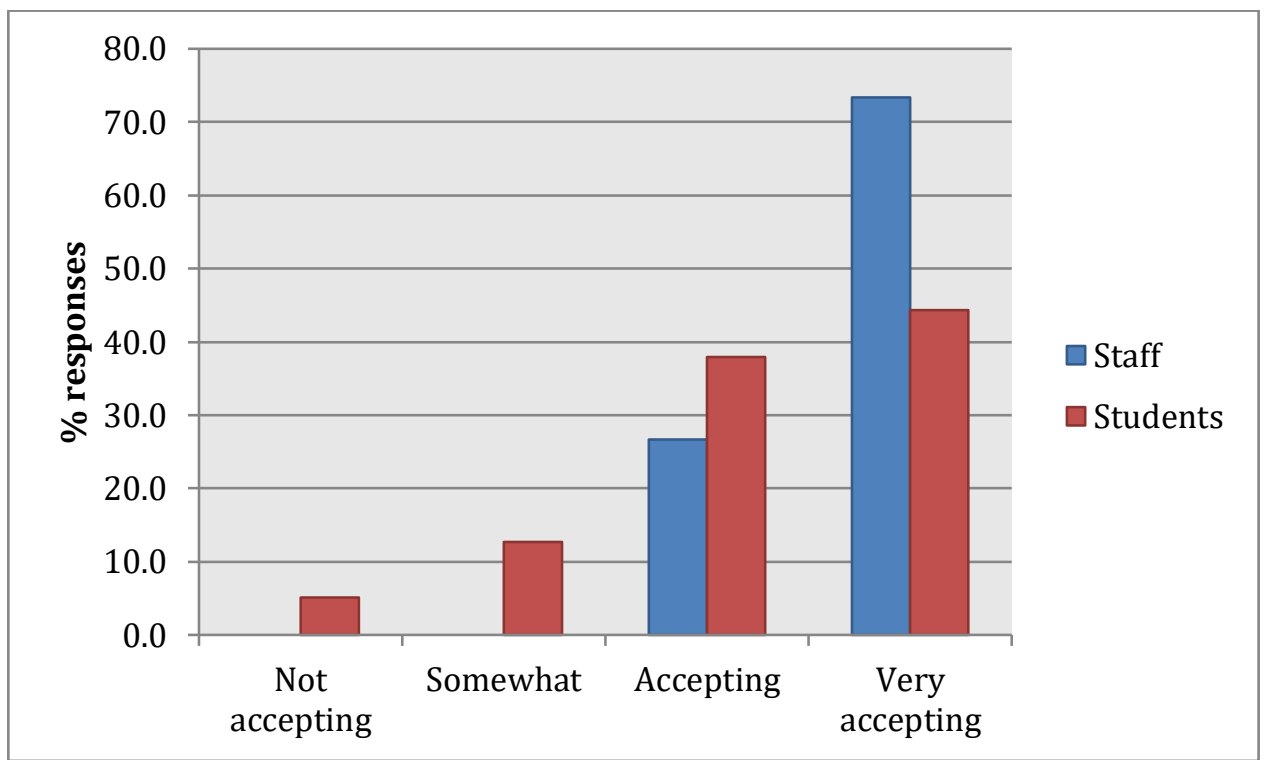

Fig. 4: Percentages of respondents ratings of how accepting they percieve they are towards LGBT people

The support group is a great start! I also believe that we need to raise awareness across our student body as it is likely some students have not had good role modeling in regards to acceptance of these students from home. Therefore they may not yet realise the harm that it may be 
causing or that LGBT students should be accepted and treated just like anyone else.

There was a strong emphasis on awareness-raising amongst the student body rather than with staff members. The one opposing comment was, "Not let them into [school] SIMPLE!" So possibly the first comment would support the second in that education around difference and acceptance may help this young person grow his/her understanding and tolerance of difference.

When asked to add any other comments 19 people responded. These responses were affirming of supporting inclusive practices and wanting the school to be a safe learning environment for all. For example,

Any person who does not fit the 'norm' (whatever that may be) is at risk of being marginalised. This includes Deaf or hearing impaired, physically challenged, overweight, and dyslexic and LGBT. We all need to learn that people are different and focus on what they can do rather than what they can't; many have challenges we may never know about.

\section{DISCUSSION}

The reconnaisance of the physical environment yielded few cues about the school culture being an accepting one specifically for LGBT students, despite their importance to such students' wellbeing. In the first instance, there was no designated place for LGBT students to meet and support each other. Another issue was that there were few explicit artefacts that normalised diverse gender identities and sexual preference. An example of an artefact that might achieve this includes posters that acknowledge and affirm gender and sexual diversity. Such artefacts were noticeably absent in the counseling rooms even, which are arguably crucial spaces for LGBT students experiencing bullying or other social and personal issues. Other possible artefacts include school uniforms; indeed, at the school under study, the uniforms required students to choose between 'male' (shorts or trousers) and 'female' (skirts). It is likely that this presented issues for gender fluid, trans-sexual, and trans-gendered students. In addition, delineating clothes for 'boys' or 'girls' in such a way communicates and reinforces heteronormative and stereotypical ideas about gender. In the future, further artefacts might be included for analysis, such as videos and other teaching material. Another facet that could be included for investigation is analysis of any school graffiti for discriminatory comments (as described by Chesir-Teran, 2003).

The majority of respondents reported that they were accepting of LGBT people, nonetheless, a significant number compared the safety of those students unfavourably to the general safety of students within the school context. Also, over one third of the respondents reported that they had seen bullying towards LGBT people at school. Given that there were only a small number of respondents who gave themselves a low rating in acceptance of LGBT people, it is possible that a few individuals perpetrate multiple episodes of bullying. 
Another point to notice is that whereas $50 \%$ of the respondents rated themselves as 'very accepting', 40\% nominated 'accepting'. It is not known what might characterise an 'accepting' person from a 'very accepting' person; however, understanding the reasons for the differences in rating might be crucial to enhancing safety for LGBT people at the school. For instance, it is possible that an accepting person might act from good will, however, a very accepting person might move beyond mere goodwill to actively promoting LGBT interests generally or defend LGBT people when discriminatory comments occur. In other words, it is possible that the difference is between internalised beliefs and an individual's ability to make direct and political action on them.

A minority of respondents gave statements that were overtly prejudiced. In this instance, individual students' rights to express an opinion are at odds with the safety of LGBT students and staff within the school. It is argued here, that all students' views must be responded to respectfully; however, in the case of views that are potentially harmful to others, that education towards tolerance is imperative. Indeed, Horn, Szalacha, and Drill (2008) state that educational settings must "provide students with the skills and knowledge they need to negotiate the increasing diverse and global world and to respect and affirm every individual's right to freedom from harm, intolerance and bigotry" (p. 810).

Sexuality-based bullying is not just a school problem, it is a societal problem and education is the key if we want to change public consciousness (Meyer \& Bayer, 2013). We must not under-estimate adolescents and their capabilities to be self-determining. Nor must we underestimate their ability to "actively construct their own understandings and form their own conclusions about fairness and rights regarding sexuality" (Horn, Szalacha, \& Drill, 2008, p. 810). Even if they continue to believe that homosexuality is wrong, one would hope that they might understand and appreciate that all have the right to be free from harassment and discrimination. In addition, such education might equip other, more accepting, students with the tools to challenge specific peers' discriminatory comments and behaviours, and to defend the rights of LGBT people.

The teachers' understanding of the antecedents for anti-LGBT behaviours is critical to preventing problems reoccurring. Hence there is value in continuing to engage in pedagogical discussions, sharing as a collective group what responses are most effective, and for all to know the long term harm bullying causes (Higdon, 2011). Research both in New Zealand and overseas discusses the value of taking a whole-school approach (Denny, et al., 2014). It is argued here, that such an approach must encapsulate the physical environment and the messages contained within it, as well as the interpersonal environment.

Jill Hermann-Wilmarth (2007) suggests that instead of LGBT issues being avoided or silenced under labels such as 'sensitive', "teachers need to bring concerns into the open and look at them through multiple lenses with their students" (Hermann-Wilmarth, 2007, p. 349). Such lenses should look to the latent and unconscious spaces of the classroom, such as its artefacts and the hidden curriculum, because these influence the perceptions and interactions that occur within them. Notwithstanding, this requires personal courage, support, sensitivity, and knowledge. Hermann-Wilmarth cites Hade (1997) in suggesting that curriculum inclusiveness can be an agent of social change, but this type of inclusiveness is "dependent on professional development and willing 
participation by faculty and staff. Implicit and explicit approval and support of high school principals is also crucial to curriculum change" (Castro \& Sujak, 2014, p. 458).

\section{Plans for ongoing improvement}

Based on the findings and reflections throughout the first phases of the study, the following plan was developed. This plan has yet to be communicated to the school community and approved by it.

1. LGBT Support Group celebration: Celebrate with a launch of the LGBT support group. This will include a planned approach to a media release. The media release will inform the wider community of the changes that the school is making to enhance inclusive school practices and ensuring that staff and students who identify as LGBT feel welcomed, safe and valued for who they are (Interpersonal environment).

2. Safe Space: Provide a safe space within the college for the LGBT support group to meet regularly (Physical \& Interpersonal environment)

3. The counselling rooms: Make improvements to the ambiance of the counselling rooms to be more welcoming and inclusive for LGBT students and staff with posters and information visual and accessible (Physical environment).

4. School Nurse \& Doctor: Support health issues relating to LGBT students (Interpersonal environment)

5. Uniforms: Present a proposal to the Board and suggest a student, staff and board focus group to review the current uniform through an inclusive lens. This could include a selection of bottom articles of clothing and tops so students are able to mix and match to suit their preferred dress attire in-line with college uniform standards and their personal choice (Physical environment).

6. Health Education: Principal and Senior Management team to reconsider the delivery of the Health curriculum programme to include LGBT awareness to health and wellbeing with a focus on normalising gender and sexual diversity (Interpersonal environment).

7. Anti-Bullying programmes: Strengthen anti-bullying programmes to include awareness to LGBT issues with particular reference to verbal insults and put-downs (Interpersonal environment). Empower students to be 'champions', i.e. challenge bullying behaviours when they see them occuring.

8. School Facilities: Property development to upgrade toilet and changing facilities around the school to 
include more gender neutral bathrooms (Physical environment).

9. School signage: Have LGBT-friendly signage displayed around the school and pictures, posters and affirming words and or quotes that acknowledge gender and sexuality diversity in positive and healthy ways (Physical environment).

10. Library: Purchase more LGBT-friendly books, both fiction and non-fiction (Physical environment).

\section{CONCLUSIONS}

Although the school is arguably a comparatively safe site for LGBT students, survey respondents indicate that further improvement is required. In addition, a reconnaissance of the physical environment identified that although there were artefacts that promoted general acceptance and support of others, there were few artefacts that supported LGBT people specifically or promoted acceptance towards them. In gathering the views of participants and evaluating the physical environment, a draft plan was developed. A whole-school approach will be taken with regard to further developing and then implementing the plan, which will most likely have an educative component as well as strategies to address the way that artefacts within the physical environment can support the inclusion of LGBT students and staff through the provision of safe spaces and challenging biased, intolerant, or heteronormative stances.

\section{ACKNOWLEDGEMENTS}

The authors thank the students and staff who participated in this research. We applaud the school for being courageous in its self-examination and willingness to share this information with others. We would also like to express our gratitude for the insightful, in-depth, and knowledgable feedback given by the two reviewers. Your guidance in shaping this article has been invaluable.

\section{Manuscript Submitted: May 15, 2017}

Revised Manuscript Received September 29, 2017

Revised Manuscript Received November 11, 2017

Manuscript Accepted: November 11, 2017 


\section{REFERENCES}

Aspin, C. \& Hutchings, J. (2007). Reclaiming the past to inform the future: Contemporary views of Māori sexuality. Culture, Health, Sexuality, 9(4), 415-427.

Castro, I. \& Sujak, M. (2014). Why can't we learn about this?: Sexual minority students navigate the official and hidden curricular spaces of high school. Education and Urban Society, 46(4), 450-473.

Chesir-Teran, D. (2003). Conceptualizing and assessing heterosexism in high schools: A setting-level approach. American Journal of Community Psychology, 31(3/4), 267-279.

Clark, T., Flemming, T., Bullen, P., Denny, S., Crengle, S., Dyson, B., Fortune, S., Lucassen, M., Peiris-John, R., Robinson, E., Rossen, F., Sheridan, J., Teevale, T., Utter, J. (2013). Youth'12 Overview: The health and wellbeing of New Zealand seconday school students in 2012. Auckland, New Zealand: The University of Auckland. Retrieved: https://www.fmhs.auckland.ac.nz/assets/fmhs/faculty/ahrg/docs/2012overview.pdf

Denny, S., Lucassen, M., Stuart, J., Fleming, T., Bullen, P., Peiris-John, R., Rossen, F., \& Utter, J. (2014). The association between supportive highschool environments and depressive symptoms and suicidality among sexual minority students. Journal of Clinical Child and Adolescent Psychology, 45(3), 1-14. doi: 10.1080/15374416.2014.958842.

Gunn, A. \& McNaughton, G. (2007). Boys and boyhood: The problems and possibilities of equity and gender diversity in early childhood settings. In

L. Keesing-Stles \& H. Hedges, Theorising early childhood practice: Emerging dialogues. (pp. 121-136). Castle Hill, NSW: Pademelon.

Gunn, A. \& Smith, L. (Eds.). (2015). Sexual cultures in Aotearoa. Dunedin, New Zealand: Otago University Press.

Grundy, S. (1994). Action research at the school level: possibilities and problems. Educational Action Research, 2(1), 23-37. doi: 10.1080/0965079940020007.

Hermann-Wilmarth, J. (2007). Full inclusion: Understanding the role of gay and lesbian texts and films in teacher education classrooms. Language Arts, 84(4), 347-356.

Higdon, M. (2011). To lynch a child: Bullying and gender non-conformity in our nation's schools. Indiana Law Journal, 86(3), 1-16.

Horn, S., Szalacha, L., \& Drill, K. (2008). Schooling, sexuality and rights: an investigation of heterosexual students' social cognition regarding sexual orientation and the rights of gay and lesbian peers in school. Journal of Social Issues, 64(4), 791-813.

Lantolf, J. (2000). Introducing sociocultural theory. Sociocultural Theory and Second Language Learning, 1, 1-26.

Lucassen, M., Clark, T., Moselen, E., Robinson, E., \& The Adolescent Health Research Group. (2014). Youth'12. The Health and Wellbeing of Secondary School Students in New Zealand: Results for Young People Attracted to the Same Sex or Both Sexes. Auckland: The University of Auckland. Retrievable from: https://www.fmhs.auckland.ac.nz/assets/fmhs/faculty/ahrg/docs/Youth'12 
\%20Young\%20People\%20Attracted\%20to\%20the\%20Same\%20or\%20B oth\%20Sexes\%20Report.pdf

Mercer, J. (2007). The challenges of insider research in educational institutions: Wielding a double edged sword and resolving delicate dilemmas. Oxford Review of Education, 33(1), 1-17. doi:10.1.1080/03054980601094651

Meyer, I. \& Bayer, R. (2013). School-based affirmative interventions: First amendment and ethical concerns. American Journal of Public Health, 103(10), 1764-1771.

McNiff, J. (2013). Action research: Principles and practice. New York, NY: Routledge.

Ministry of Education. (2007). The New Zealand Curriculum. Wellington, New Zealand: Learning Media. Retrievable from http://nzcurriculum.tki.org.nz/The-New-Zealand-Curriculum

Nairn, K. \& Smith, A. (2010). Taking students seriously: Their rights to be safe at school. Gender and Education, 15, 133-149.

Skinner, E., Wellborn, J., \& Connell, J. (1990). What it takes to do well in school and whether l've got it: A process model of perceived control and children's engagement and achievement in school. Journal of Educational Psychology, 82(1), 22-32. doi.org/10.1037/00220663.82 .1 .22

Timperley, H., Kaser, L. \& Halbert, J. (2014). A framework for transforming learning in schools: Innovation and the spiral of inquiry. Centre for Strategic Education: Melbourne, Australia. Retrieved: https://educationcouncil.org.nz/sites/default/files/49.\%20Spiral\%20of\%20 Inquiry\%20Paper\%20-\%20Timperley\%20Kaser\%20Halbert.pdf 


\section{ABOUT THE AUTHOR(S) \\ WENDY HEMI}

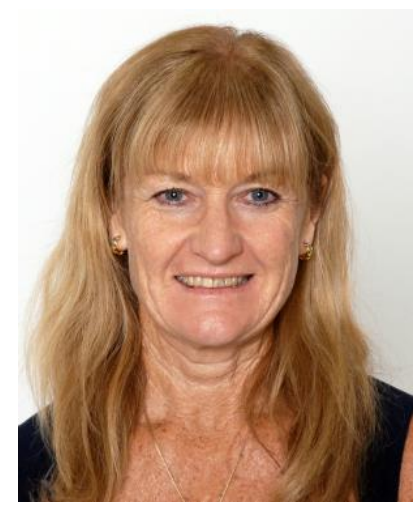

Wendy Hemi has an education professional career spanning 40 years, predominantly in Early Childhood Education, working as a teacher, head teacher and senior teacher with several Kindergarten Associations in the lower North Island New Zealand. Two years ago, she made a career shift, taking up a position as Pouarahi/School Guidance Counsellor at a secondary school. She has recently completed an Education (Counselling and Guidance) Post Graduate qualification at Massey University.

\section{ANITA MORTLOCK \\ Victoria University, Wellington}

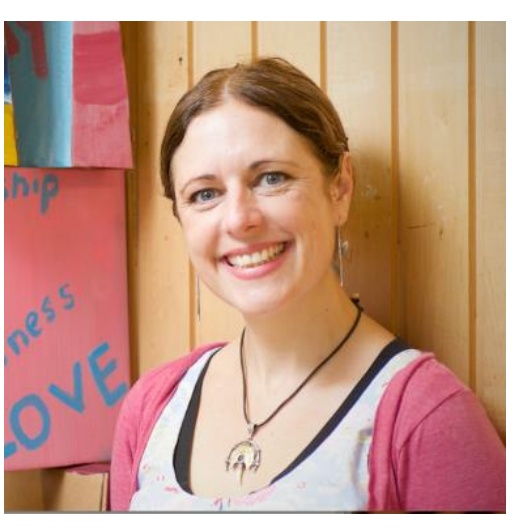

A former ECE teacher, Anita Mortlock is now a lecturer at Victoria University in the School of Education. Her research interest is the intersection between the official world of educational settings (such as policy) and the lived experiences of those who operate in those educational settings. A further key research area is the efficacy of pedagogy involving large groups. At present, she is involved in several research projects that span different stages of the education sector, including tertiary learners.

\footnotetext{
The opinions expressed are those of the paper author(s) and not the New Zealand Journal of Teachers' Work. Copyright is held by individual authors but offprints in the published format only may be distributed freely by individuals provided that the source is fully acknowledged. [ISSN-1176-6662]
} 